\title{
Synthesis and characterization of some heteroleptic copper(II) complexes based on meso-substituted dipyrrins
}

\author{
RAKESH KUMAR GUPTA, MAHENDRA YADAV, RAMPAL PANDEY and \\ DAYA SHANKAR PANDEY* \\ Department of Chemistry, Faculty of Science, Banaras Hindu University, Varanasi 221005, India \\ e-mail: dspbhu@bhu.ac.in
}

\begin{abstract}
The syntheses and characterizations of meso-substituted dipyrrins, 5-(4-imidazol-1-yl-phenyl)dipyrromethene (4-impdpm), 5-(4-nitro-imidazol-1-yl-phenyl)-dipyrromethene, (4-nimpdpm), 5-(4-benzimidazol1-yl-phenyl)-dipyrromethene (4-bimp-dpm) and heteroleptic complexes $\left[\mathrm{Cu}_{3}(4 \text {-impdpm })_{2}(\mathrm{hfacac})_{4}\right] \mathbf{1},[\mathrm{Cu}(4-$ nimpdpm)(acac) $]$ 2, $[\mathrm{Cu}(4-$ nimpdpm $)(\mathrm{hfacac})] 3$, [\{Cu(4-bimpdpm)(acac) $\left.\}_{\mathrm{n}}\right] \mathbf{4}$ and $[\{\mathrm{Cu}(4$-bimpdpm)(hfacac) $\left.\}_{n}\right] \mathbf{5}$, imparting acetylacetonato (acac) and hexafluoroacetylacetonato (hfacac) groups as co-ligand have been described. The dipyrrins and complexes 1-5 have been characterized by elemental analyses and spectral (IR ESI-MS, NMR, electronic absorption and emission) studies. Crystal structures of $\mathbf{1}, \mathbf{3}$ and $\mathbf{4}$ have been authenticated by X-ray single crystal analyses. The reaction between 4-impdpm and $\mathrm{Cu}(\mathrm{hfacac})_{2}$ gave a trimetallic complex, under analogous conditions 4-nimpdpm and 4-bimpdpm reacted with $\mathrm{Cu}(\mathrm{acac})_{2}$ and $\mathrm{Cu}(\mathrm{hfacac})_{2} \cdot 2 \mathrm{H}_{2} \mathrm{O}$ to afford mononuclear $(\mathbf{2}, \mathbf{3})$ and $1 \mathrm{D}$ polymeric $(\mathbf{4}, \mathbf{5})$ complexes.
\end{abstract}

Keywords. Coordination polymers; meso-substituted dipyrrins; heteroleptic; acetylacetonato; hexafluoroacetylacetonato; copper complexes.

\section{Introduction}

The chemistry of coordination polymers has seen a large surge during past couple of decades because of their intriguing architectures, topologies, and potential application in diverse areas. ${ }^{1-9}$ With an objective of developing functional materials possessing desirable properties numerous systems have been synthesized through the judicious choice of ligands and metal ions. ${ }^{10-15}$ The creation of coordination polymers largely depend on geometry of the metal ions, nature of the ligand, metal to ligand ratio, solvent systems, counter anions and the $p \mathrm{H}$ of reaction medium. ${ }^{16-19}$ Among these, the choice of ligand plays crucial role in the formation of coordination polymers. In addition, the design and synthesis of dipyrromethenes (dipyrrins) has been attractive because of their rather easy synthesis and functionalization as well as monoanionic and chelating nature of their conjugate base and extensive use in various areas. ${ }^{20-28} \mathrm{~A}$ large number of charge neutral homo-/heteroleptic complexes and supramolecular clusters imparting dipyrrins has been synthesized and thoroughly studied. ${ }^{20,21}$ It has been established that suitably designed meso-substituted dipyrrins find wide applications in the synthesis of extended homo-/ heterometallic architectures. ${ }^{20-22}$

\footnotetext{
${ }^{*}$ For correspondence
}

Further, imidazolyl-dipyrrins are of particular interest in materials chemistry and life sciences. ${ }^{29-31}$ With an objective of developing extended architectures based on meso-substituted dipyrrins and to examine the role of meso-substituent on ensuing complexes, 4-impdpm, 4-nimpdpm and 4-bimpdpm have been synthesized and their reactivity examined with $\mathrm{Cu}(\mathrm{II})$ complexes $\mathrm{Cu}(\mathrm{acac})_{2}$ and $\mathrm{Cu}(\mathrm{hfacac})_{2} \cdot 2 \mathrm{H}_{2} \mathrm{O}$. Through this contribution we present the synthesis and characterization of meso-substituted dipyrrins and $\mathrm{Cu}(\mathrm{II})$ complexes $\quad\left[\mathrm{Cu}_{3}(4 \text {-impdpm })_{2}(\text { hfacac })_{4}\right] \quad \mathbf{1}, \quad[\mathrm{Cu}(4-$ nimpdpm)(acac)] 2, [Cu(4-nimpdpm)(hfacac)] $\mathbf{3}$, $\left[\{\mathrm{Cu}(4 \text {-bimpdpm })(\mathrm{acac})\}_{\mathrm{n}}\right] \mathbf{4}$, and [ $\{\mathrm{Cu}(4$-bimpdpm)(hfacac) $\left.\}_{\mathrm{n}}\right]$ 5. Also, we present here X-ray single crystal structures of $\mathbf{1}, 3$ and 4 .

\section{Experimental}

The solvents were rigorously purified by standard procedures prior to their use. ${ }^{32}$ Imidazole, 4nitroimidazole, benzimidazole, 4-fluorobenzaldehyde, trifluoroacetic acid (TFA), 2,3-dichloro-5,6-dicyano1,4-benzoquinone (DDQ), triethylamine, $\mathrm{Cu}(\mathrm{hfacac})_{2} \cdot-$ $2 \mathrm{H}_{2} \mathrm{O}$ and silica gel (200-400 mesh) were procured from Sigma Aldrich Chemical Co., USA and used as received without further purifications. The ligands 
4-impdpm, 4-nimpdpm and 4-bimpdpm were synthesized by the procedure described by Magdolen et al. with slight modifications ${ }^{33}$ and the precursor complex $\mathrm{Cu}(\mathrm{acac})_{2}$ following literature procedure. ${ }^{34}$ Elemental analyses for $\mathrm{C}, \mathrm{H}$ and $\mathrm{N}$ were performed on an Exeter Analytical Inc. Model CE-440 Elemental Analyzer. IR spectra (4000-400 $\left.\mathrm{cm}^{-1}\right)$ were acquired on a Varian 3300 FT-IR spectrometer. Electronic absorption and emission spectra were obtained on Shimadzu UV-1701 and Varian Cary Eclipse Fluorescence spectro-photometers, respectively. ${ }^{1} \mathrm{H}(300 \mathrm{MHz}) \mathrm{NMR}$ spectra was acquired on a JEOL AL300 FT-NMR spectrometer using tetramethylsilane (TMS) as an internal reference. Room temperature magnetic susceptibility measurements were performed on a Cahn-Faraday balance using $\mathrm{Hg}\left[\mathrm{Co}(\mathrm{SCN})_{4}\right]$ as a calibrant.

\subsection{Syntheses}

2.1a 5-(4-imidazol-1-yl-phenyl)-dipyrromethane (4impdpm): To a flask containing pyrrole $(19.34 \mathrm{~g})$, 4-imidazol-1-yl-benzaldehyde $(3.44 \mathrm{~g}, 0.02 \mathrm{~mol})$ was added and heated at $120^{\circ} \mathrm{C}$ with stirring under inert atmosphere for $24 \mathrm{~h}$. After cooling to ambient temperature it was concentrated to dryness under reduced pressure and the crude product purified by column chromatography [alumina; ethylacetate: dichloromethane (1: 1)]. Yield: $38 \%$ (2.19 g). Anal. Calc. for $\mathrm{C}_{18} \mathrm{H}_{16} \mathrm{~N}_{4}$ : C, 74.96; H, 5.60; N, 19.44\%. Found: C, 75.29; H, 5.47; N, 19.52\%. ${ }^{1} \mathrm{H}$ NMR $\left(\mathrm{CDCl}_{3}, \delta \mathrm{ppm}\right): 5.54$ (s, $1 \mathrm{H}$, meso-H), $5.92(\mathrm{~s}, 2 \mathrm{H}$, pyr-H), $6.18(\mathrm{q}, 2 \mathrm{H}, J=$ $3.0 \mathrm{~Hz}$, pyr-H), 6.74 (s, 2H, pyr-H), 7.19-7.32 (m, 6H), 7.80 (s, 1H, imi-H), 8.04 (bs, 2H, NH). IR (KBr pellet, $\mathrm{cm}^{-1}$ ): 3255, 3115, 2966, 1655, 1567, 1518, 1431, 1305, 1253, 1112, 1058, 819, 774, 724.

2.1b 5-(4-(4-nitro-imidazol)-1-yl-phenyl)-dipyrromethane (4-nimpdpm): It was prepared by following the above procedure for 4-impdpm using 4-(4-nitro-imidazol1-yl)-benzaldehyde (4.34 g, $0.02 \mathrm{~mol})$. Yield: $40 \%$ (2.67 g). Anal. Calc. for $\mathrm{C}_{18} \mathrm{H}_{15} \mathrm{~N}_{5} \mathrm{O}_{2}: \mathrm{C}, 64.84 ; \mathrm{H}$, 4.54; N, 21.01\%. Found: C, 65.00; H, 4.62; N, 21.30\%. ${ }^{1} \mathrm{H} \mathrm{NMR}\left(\mathrm{CDCl}_{3}, \delta \mathrm{ppm}\right): 5.46(\mathrm{~s}, 1 \mathrm{H}$, meso-H), 5.89 (s, 2H, pyr-H), 6.18 (s, 2H, pyr-H), 6.70 (s, 2H, pyr-H), 7.35-7.40 (m, 4H), 7.71 (s, 1H, imi-H), 8.04 (bs, 2H, $\mathrm{NH}), 8.06$ (s, 1H, imi-H). IR ( $\mathrm{KBr}$ pellet, $\left.\mathrm{cm}^{-1}\right)$ : 3248, 3124, 2968, 1678, 1610, 1590, 1542, 1514, 1490, 1426, 1406, 1350, 1304, 1268, 1122, 1092, 1068, 1024, 822, $774,732$. 2.1c 5-(4-benzimidazol-1-yl-phenyl)-dipyrromethane (4-bimpdpm): It was prepared by following the above procedure for 1 using 4-impdpm $(4.44 \mathrm{~g}, 0.02 \mathrm{~mol})$. Yield: $50 \%$ (3.85 g). Anal. Calc. for $\mathrm{C}_{22} \mathrm{H}_{18} \mathrm{~N}_{4}$ : C, 78.08; H, 5.36; N, 16.56\%. Found: C, 78.15; H, 5.39; $\mathrm{N}, 16.49 \% .{ }^{1} \mathrm{H}$ NMR $\left(\mathrm{CDCl}_{3}, \delta \mathrm{ppm}\right): 5.59(\mathrm{~s}, 1 \mathrm{H}$, meso-H), 5.60 (s, 2H, pyr-H), 6.18 (s, 2H, pyr-H), 6.77 (s, 2H, pyr-H), 7.35-7.40 (m, 6H), $7.56(\mathrm{~s}, 1 \mathrm{H}), 7.79$ (s, 1H), 7.82 (s, 1H, imi-H), 8.58 (bs, 2H, NH), IR ( $\mathrm{KBr}$ pellet, $\left.\mathrm{cm}^{-1}\right)$ : 3256, 3122, 2961, 1676, 1615, 1581 $1543,1517,1492,1423,1408,1350,1305,1265,1120$, 1095, 1068, 1025, 823, 773, 730.

2.1d $\left[\mathrm{Cu}_{3}(4-i m p d p m)_{2}(\text { hfacac })_{4}\right]$ (1): To a stirring ice cooled dichloromethane solution $(50 \mathrm{~mL})$ of 4-impdpm $(0.288 \mathrm{~g}, 0.001 \mathrm{~mol})$, DDQ $(0.228 \mathrm{~g}$, $1.0 \mathrm{mmol})$ dissolved in benzene $(30 \mathrm{~mL})$ was added drop-wise and stirred for an hour. A methanolic $(20 \mathrm{~mL})$ solution of $\mathrm{Cu}(\mathrm{hfacac})_{2} \cdot 2 \mathrm{H}_{2} \mathrm{O}(0.496 \mathrm{~g}, 0.001 \mathrm{~mol})$ was added to it and stirred for $20 \mathrm{~min}$. The reaction mixture was evaporated to dryness and crude product purified by column chromatography $\left(\mathrm{SiO}_{2}: \mathrm{CHCl}_{3}\right.$ with $1 \%$ $\mathrm{MeOH})$ to afford a red solid. Dichroic reddish-green crystals of 1 were obtained from $\mathrm{CH}_{2} \mathrm{Cl}_{2}$ / hexane (1 : 1) solution. Yield: $30 \%(0.190 \mathrm{~g})$. Anal. Calc. for $\mathrm{C}_{36} \mathrm{H}_{26} \mathrm{~N}_{8} \mathrm{Cu}: \mathrm{C}, 68.18 ; \mathrm{H}, 4.13 ; \mathrm{N}, 17.67 \%$. Found: $\mathrm{C}$, 68.38; H, 4.30; N, $17.55 \%$. ESI-MS $(\mathrm{m} / \mathrm{z})$ obs (calcd.): $634[\mathrm{M}+\mathrm{H}]^{+}$(634). IR (KBr pellet, $\mathrm{cm}^{-1}$ ): 2923, 1606, 1546, 1377, 1335, 1244, 1185, 1109, 1035, 995, 893, 809, 775, 727, 654. UV-Vis. $\left(\mathrm{CH}_{2} \mathrm{Cl}_{2}, \lambda_{\max } \mathrm{nm} ; \varepsilon\right.$, $\mathrm{M}^{-1} \mathrm{~cm}^{-1}$ ): 496 (39880), 332 (15655), 300 (33852).

2.1e [Cu(4-nimpdpm)(acac)] (2): It was prepared following the above procedure for 1 using 4nimpdpm $(0.288 \mathrm{~g}, 0.001 \mathrm{~mol})$ and $\mathrm{Cu}(\mathrm{acac})_{2}(0.288 \mathrm{~g}$, $0.001 \mathrm{~mol})$. Yield: $35 \%(0.172 \mathrm{~g})$. Anal. Calc. for $\mathrm{C}_{23} \mathrm{H}_{19} \mathrm{~N}_{5} \mathrm{O}_{4} \mathrm{Cu}: \mathrm{C}, 56.04 ; \mathrm{H}, 3.88 ; \mathrm{N}, 14.21 \%$. Found: $\mathrm{C}, 56.24 ; \mathrm{H}, 4.00 ; \mathrm{N}, 14.33 \%$. ESI-MS $(\mathrm{m} / \mathrm{z})$ obs (calcd.): $492[\mathrm{M}]^{+}$(492). IR (KBr pellet, $\mathrm{cm}^{-1}$ ): 2906, 1582, 1550, 1406, 1392, 1378, 1336, 1244, 1206, 1178, $1118,1080,1028,994,892,818,770,732,654$. UVVis. $\left(\mathrm{CH}_{2} \mathrm{Cl}_{2}, \lambda_{\max } \mathrm{nm} ; \varepsilon \mathrm{M}^{-1} \mathrm{~cm}^{-1}\right): 490$ (39764), 320 (15770), 233 (21567).

2.1f [Cu(4-nimpdpm)(hfacac)] (3): It was synthesized adopting the above procedure for 1 using 4nimpdpm and $\mathrm{Cu}(\mathrm{hfacac})_{2} \cdot 2 \mathrm{H}_{2} \mathrm{O}$. Yield: $28 \%$ (0.168 g). Anal. Calc. for: C, 46.00; H, 2.18; N, 11.65\%. Found: C, 45.88; H, 2.32; N, $11.79 \%$. ESI-MS $(m / z)$ obs (calcd.): $600[\mathrm{M}]^{+},(600)$. IR (KBr pellet, $\left.\mathrm{cm}^{-1}\right): 2923,1648$, 
$1552,1456,1408,1378,1340,1302,1248,1212,1146$, 1114, 1064, 1034, 1000, 964, 890, 818, 778, 672. UV-Vis. $\left(\mathrm{CH}_{2} \mathrm{Cl}_{2}, \lambda_{\max } \mathrm{nm} ; \varepsilon \mathrm{M}^{-1} \mathrm{~cm}^{-1}\right)$ : 491 (32945), 318 (17354), 230 (22142).

2.1g $\left[\{C u(4-b i m p d p m)(a c a c)\}_{n}\right] \quad$ (4): This compound was prepared following the above procedure for 1 using 4-bimpdpm and $\mathrm{Cu}(\mathrm{acac})_{2}$ in 1:1 molar ratio. Yield: $33 \%$ (0.232 g). Anal. Calc. for $\mathrm{C}_{28} \mathrm{H}_{25} \mathrm{~N}_{5} \mathrm{O}_{2} \mathrm{Cu}_{2}$ : $\mathrm{C}, 56.94, \mathrm{H}, 4.27 ; \mathrm{N}, 11.86 \%$. Found: $\mathrm{C}, 56.78 ; \mathrm{H}$, 4.23; N, 11.79\%. ESI-MS ( $m / z)$ obs (calcd.): $498[\mathrm{M}]^{+}$ (498). IR (KBr pellet, $\mathrm{cm}^{-1}$ ): 2925, 1649, 1550, 1450, 1406, 1376, 1340, 1305, 1246, 1213, 1146, 1113, 1065 , 1034, 1003, 965, 895, 816, 778, 675. UV-Vis. $\left(\mathrm{CH}_{2} \mathrm{Cl}_{2}\right.$, $\left.\lambda_{\max } \mathrm{nm} ; \varepsilon \mathrm{M}^{-1} \mathrm{~cm}^{-1}\right): 496$ (22 245), 298 (19180), 231 (18605).

2.1h $\quad\left[\{C u(4-b i m p d p m)(h f a c a c)\}_{n}\right] \quad$ (5): It was prepared following the above procedure for $\mathbf{1}$ using 4-bimpdpm and $\mathrm{Cu}(\mathrm{hfacac})_{2} \cdot 2 \mathrm{H}_{2} \mathrm{O}$ in $1: 1$ molar ratio. Yield: $28 \%(0.168 \mathrm{~g})$. Anal. Calc. for $\mathrm{C}_{28} \mathrm{H}_{19} \mathrm{Cu}_{2} \mathrm{~F}_{6} \mathrm{~N}_{5} \mathrm{O}_{2}$ : C, 48.14; $\mathrm{H}, 2.74 ; \mathrm{N}, 10.03 \%$. Found: C, 48.16; H, 2.72; N, 10.04\%. ESI-MS $\left(\mathrm{m} / \mathrm{z}\right.$ ) obs (calcd.): $606[\mathrm{M}+\mathrm{H}]^{+}(606)$. IR (KBr pellet, $\mathrm{cm}^{-1}$ ): 2926, 1646, 1555, 1525, 1460, 1408, 1382, 1342, 1257, 1209, 1147, 1114, 1032, 1036, 1000, 799, 744, 672. UV-Vis. $\left(\mathrm{CH}_{2} \mathrm{Cl}_{2}, \lambda_{\max } \mathrm{nm} ; \varepsilon \mathrm{M}^{-1} \mathrm{~cm}^{-1}\right): 502$ (12592), 468 (25092), 340 (09536), 232 (17698).

\section{$2.2 X$-ray crystallography}

Preliminary data on the space group and unit cell dimensions as well as intensity data for $\mathbf{1}$ and $\mathbf{3}$ were collected on OXFORD DIFFRACTION $\mathrm{X}$ CALIBUR-S and for $\mathbf{4}$ on a Bruker APEX II with Mo-K $\alpha$ radiation $(\lambda=0.71073 \AA)$. The structures were solved by direct methods and refined using SHELX-97. ${ }^{35}$ Non-hydrogen atoms were refined with anisotropic thermal parameters. All the hydrogen atoms were geometrically fixed and refined using a riding model. Computer program PLATON was used for analysing the interaction and stacking distances. ${ }^{36}$ CCDC-789391 (1), 789392 (3) and 832184 (4) contains supplementary crystallographic data for this paper. It can be obtained free of charge via http://www.ccdc.cam.ac.uk/conts/retrieving.html (or from CCDC, 12 Union Road, Cambridge CB21EZ, UK; Fax: + 44-1223-336033; E-mail: deposit@ccdc.cam.ac.uk).

\section{Results and discussion}

\subsection{Synthesis}

The aldehydes 4-imidazol-1-yl-benzaldehyde, 4-(4-nitro-imidazol-1-yl)-benzaldehyde, and 4benzimidazol-1-yl-benzaldehyde were prepared by the reaction of 4-fluorobenzaldehyde with imidazole, 4-nitroimidazole and benzimidazole, respectively following literature procedure with slight modifications (see Supplementary Information). ${ }^{33}$ Condensation of the respective aldehydes with pyrrole in the presence of catalytic amounts of TFA $(0.1 \mathrm{mM})$ afforded 5-(4-imidazol-1-yl-phenyl)-dipyrromethane, 5-(4-nitro-imidazol)-1-yl-phenyl)-dipyrromethane and 5-(4-benzimidazol-1-yl-phenyl)-dipyrromethane in reasonably good yields. ${ }^{28}$ Although, the synthesis of 5-(4-imidazol-1-yl-phenyl)-dipyrromethane has already been reported ${ }^{22}$ we prepared this compound adopting a different method. The synthesis of dipyrrins were achieved by oxidation of respective dipyrromethanes using DDQ in a mixture of benzene and dichloromethane. ${ }^{28,37} \mathrm{~A}$ simple route for the synthesis of dipyrromethanes and corresponding dipyrrins is depicted in scheme 1. The dipyrrinato complexes 1-5 were obtained in good yield by in situ reaction of dipyrrins with metal precursors (scheme $2 a, b$ ).

The reaction of $\mathrm{Cu}(\text { hfacac })_{2} \cdot 2 \mathrm{H}_{2} \mathrm{O}$ with 4impdpm (1:1 molar ratio) gave a trinuclear complex $\left[\mathrm{Cu}_{3}(\mathrm{hfacac})_{4}(4 \text {-impdpm })_{2}\right] \mathbf{1}$, while mononuclear complexes $[\mathrm{Cu}(\mathrm{acac})(4-\mathrm{nimpdpm})] 2$, and $[\mathrm{Cu}(\mathrm{hfacac})(4-$ nimpdpm)] 3 were obtained from the reactions of $\mathrm{Cu}(\mathrm{acac})_{2} / \mathrm{Cu}(\mathrm{hfacac})_{2} \cdot 2 \mathrm{H}_{2} \mathrm{O}$ with 4-nimpdpm under analogous conditions. On the other hand, 4bzimpdpm reacted with $\mathrm{Cu}(\mathrm{acac})_{2} / \mathrm{Cu}(\mathrm{hfacac})_{2}$ to afford 1D polymers $\left[\{\mathrm{Cu}(4-\mathrm{bimpdpm})(\mathrm{acac})\}_{\mathrm{n}}\right] \mathbf{4}$ and $\left[\{\mathrm{Cu}(4-\text { bimpdpm })(\text { hfacac })\}_{\mathrm{n}}\right]$ 5. The complexes 1-5 are air-stable, crystalline solids, soluble in common organic solvents viz., dichloromethane, chloroform, acetone, acetonitrile, dimethylsulphoxide, dimethylformamide and insoluble in water, methanol, diethyl ether, petroleum ether, $n$-hexane, benzene and toluene. The characterization of dipyrromethanes and complexes 1-5 have been achieved by satisfactory elemental analyses, and spectral (IR, mass, electronic absorption and emission) studies.

\subsection{Spectral studies}

The infra red spectral data of $\mathbf{1 - 5}$ is summarized in experimental section alongwith other characterization data of the complexes. IR spectra of the complexes 


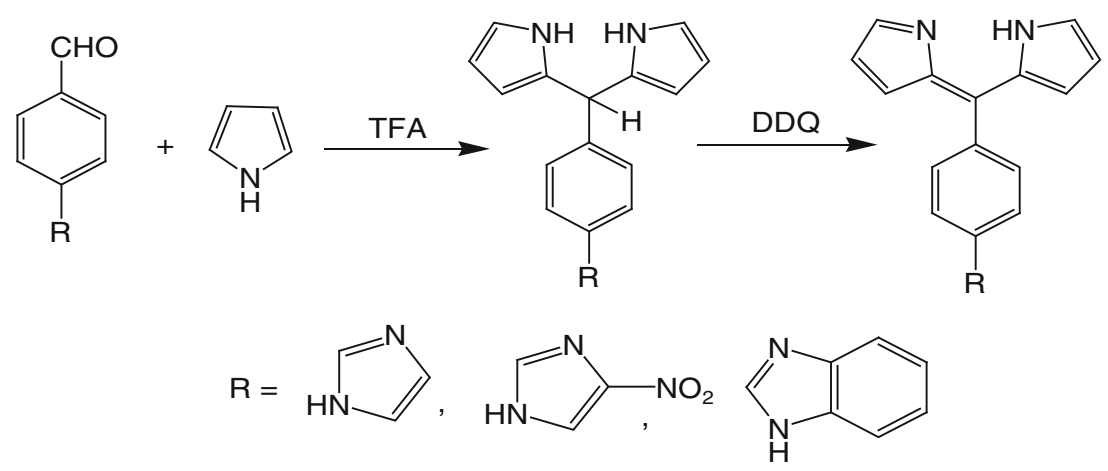

Scheme 1. Synthesis of dipyrrins.

under study displayed bands at $\sim 1546 \mathrm{~cm}^{-1}$ assignable to $v_{\mathrm{C}=\mathrm{Npyr}}$. Alongwith $v_{\mathrm{C}=\mathrm{Npyr}}$ vibrations $\mathbf{1}, \mathbf{3}$ and $\mathbf{5}$ exhibited bands due to $v_{\mathrm{C}=\text { Ohfacac }}$ at $\sim 1648 \mathrm{~cm}^{-1}$. Similarly, the complexes containing acac ( 2 and $\mathbf{5}$ ) displayed bands at $\sim 1588 \mathrm{~cm}^{-1}$ assignable to $v_{C=O a c a c}{ }^{20-22,38}$ The IR spectral data supported formation of the respective complexes.

The electronic absorption and emission spectra of 1-5 were acquired in dichloromethane and resulting data is summarized in table 3 . In its UV-vis. spectra, 1-4 displayed intense low energy transitions at $\sim 495,492,491$ and $496 \mathrm{~nm}$ alongwith high energy bands at $\sim 332,300(\mathbf{1}), 320,233(\mathbf{2}), 318,230(\mathbf{3})$, 298, 230 (4). Complex 5 displayed low energy bands at 502 and $468 \mathrm{~nm}$, while high energy transitions appeared at 340 and $233 \mathrm{~nm}$. Intense low-energy transitions in the spectra of respective complexes have been assigned to charge-transfer processes associated with dipyrrin ligands ${ }^{25-28}$ and bands in the region $\sim 230-340 \mathrm{~nm}$ have been assigned to the ligand centred intra-ligand transitions. ${ }^{39,40}$ The complexes 1-3 are non-fluorescent at room temperature, while 4-5 display weak fluorescence. ${ }^{41}$ The non fluorescent behaviour of $\mathbf{1}-\mathbf{3}$ can be ascribed to the MLCT (metal to ligand charge transfer) transitions from paramagnetic $\mathrm{Cu}$ (II) core to $\pi$ chromophore of the respective ligands along with its intrinsic quenching nature. ${ }^{42}$ In contrast, weak fluorescence displayed by $\mathbf{4}(572 \mathrm{~nm})$ and $\mathbf{5}(555 \mathrm{~nm})$ may be attributed to the extended conjugation in 4-bimpdpm relative to 4-impdpm, which dominates over MLCT

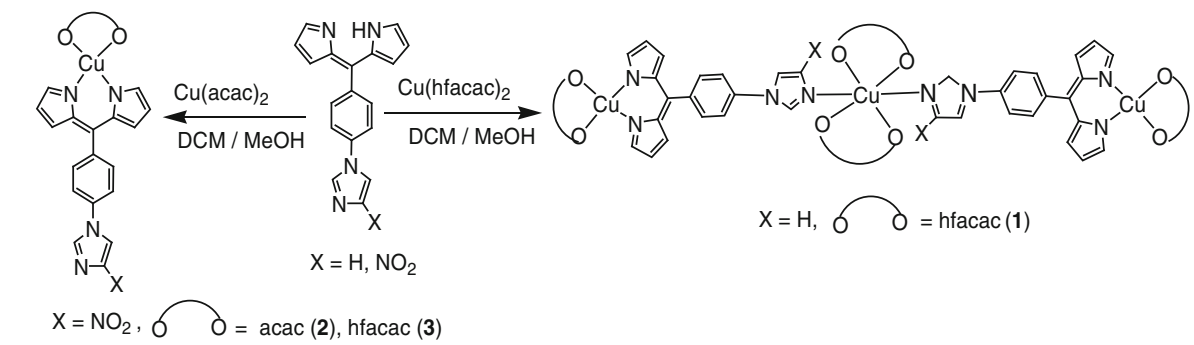

(a)

(b)

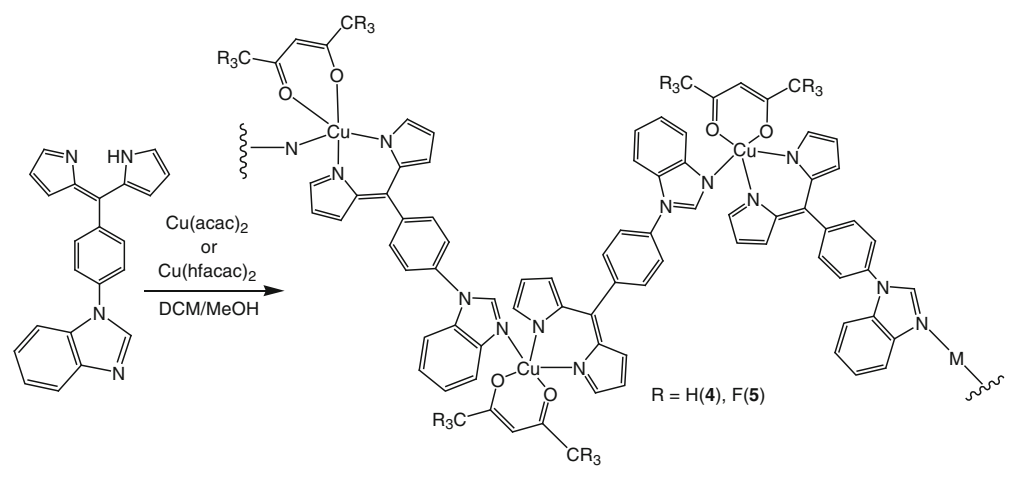

Scheme 2. Synthesis of complexes 1-5. 
transitions in copper (II) complexes. Stronger fluorescence of $\mathbf{5}$ in comparison to $\mathbf{4}$ may be related to the presence of electron withdrawing hfacac as a co-ligand instead of acac.

\subsection{Magnetic measurements}

The room temperature $\left(28.2^{\circ} \mathrm{C}\right)$ magnetic moment $\left(\mu_{e f f}\right)$ of the complexes were found to be $2.12(\mathbf{1}), 2.18$ (2), 2.13 (3), 1.98 (4) and 1.95 B.M (5). These fall in the range for spin only value (1.70-2.20), suggesting that the metal centre in these complexes contains one unpaired electron and supported the formation of $\mathrm{Cu}(\mathrm{II})$ complexes.

\subsection{Description of the crystal structures}

Structures of 1,3 and 4 have been authenticated crystallographically. Details about the data collection and refinement are gathered in table 1 . Selected geometrical parameters are summarized in table 2 and crystal structures depicted in figures 1, 2 and S6 (Supporting information figure S6). Heteroleptic trinuclear complex 1 contains three copper centres bonded to each other through bridging dipyrrin ligand. The immediate coordination geometry about $\mathrm{Cu} 2$ centre is octahedral and defined by four oxygen donors from two independent hfacac co-ligands and imidazolyl nitrogens from two different 4-impdpm ligands (figure 1). On the other hand, $\mathrm{Cu} 1 / \mathrm{Cu} 1$ _ 1 cetres displayed distorted square-planar geometry defined by two oxygen donors from hfacac, and the pyrrolyl nitrogens of the 4-impdpm. The $\mathrm{Cu}-\mathrm{N}$ and $\mathrm{Cu}-\mathrm{O}$ bond distances about the square planar $\mathrm{Cu}(\mathrm{II})$ centres are in the range of 1.912-1.923 $\AA$ and 1.955-1.956 A, respectively. The $\mathrm{N}(\mathrm{O})-\mathrm{Cu}-\mathrm{N}(\mathrm{O})$ bond angles fall in the range of 90.12 93.24 (table 2). ${ }^{20-22,38}$ The angle $(\omega)$ between $\mathrm{CuO}_{2}$ and $\mathrm{CuN}_{2}$ planes has been found to be $25.14^{\circ}$, which clearly suggested distortion from regular square planar geometry. The $\mathrm{Cu}-\mathrm{N}$ and $\mathrm{Cu}-\mathrm{O}$ bond distances about the octahedral $\mathrm{Cu} 2$ are slightly longer in comparison to the square planar $\mathrm{Cu}$ (II) centres (table 2). The $\mathrm{Cu}-\mathrm{O}$ (hfacac) bonds distances are not identical, it shows one short (Cu2-O3/Cu2-O3_3, 2.003 $\mathrm{A})$ and one long $(\mathrm{Cu} 2$ O4/Cu2-O4_4, 2.259 ̊) bond. The observed elongation of the bond distances may be ascribed to the Jahn-Teller distortion.

Complex 3 crystallizes in monoclinic system with $P 2_{1} / c$ space group. The immediate coordination geometry about $\mathrm{Cu}(\mathrm{II})$ in this complex is distorted square

Table 1. Crystal data and structure refinement parameters for 1, 3 and $\mathbf{4}$.

\begin{tabular}{|c|c|c|c|}
\hline & 1 & 3 & 4 \\
\hline Empirical formula & $\mathrm{C}_{56} \mathrm{H}_{30} \mathrm{~F}_{24} \mathrm{~N}_{8} \mathrm{O}_{8} \mathrm{Cu}_{3}$ & $\mathrm{C}_{23} \mathrm{H}_{13} \mathrm{~F}_{6} \mathrm{~N}_{5} \mathrm{O}_{4} \mathrm{Cu}$ & $\mathrm{C}_{21} \mathrm{H}_{17} \mathrm{Cu}_{1} \mathrm{~N}_{3} \mathrm{O}_{1}$ \\
\hline Crystal system & Triclinic & Monoclinic & Orthorhombic \\
\hline Space group & $P-1$ & $P 2_{1} / c$ & $P_{212121}$ \\
\hline$a(\AA)$ & $15.6718(10)$ & $29.8569(6)$ & $8.6919(13)$ \\
\hline$b(\AA)$ & $17.1682(13)$ & $11.2531(3)$ & $15.754(2)$ \\
\hline$c(\AA)$ & $18.6430(14)$ & $6.6573(2)$ & $16.664(3)$ \\
\hline$\alpha(\operatorname{deg})$ & $64.257(7)$ & 90.00 & 90.00 \\
\hline$\beta$ (deg) & $73.389(6)$ & $95.222(2)$ & 90.00 \\
\hline$\gamma(\operatorname{deg})$ & $79.259(6)$ & 90.00 & 90.00 \\
\hline$V\left(\AA^{3}\right), Z$ & $4318.4(5), 2$ & $2227.45(10), 4$ & $2281.9(6), 5$ \\
\hline$\lambda(\AA)$ & 0.71073 & 0.71073 & 0.71073 \\
\hline Colour and habbit & Orange, block & Red, thin-plate & Red, needle \\
\hline$T(\mathrm{~K})$ & $150(2)$ & $150(2)$ & 293(2) \\
\hline Reflns collected & 32866 & 10536 & 14949 \\
\hline Reflns/restraint/params & $15170 / 0 / 1339$ & $3907 / 0 / 352$ & $5596 / 0 / 310$ \\
\hline$D_{\text {calcd }}\left(\mathrm{Mg} \mathrm{m}^{-3}\right)$ & 1.834 & 1.792 & 1.450 \\
\hline$\mu\left(\mathrm{mm}^{-1}\right)$ & 1.240 & 1.076 & 0.990 \\
\hline GOF on $F^{2}$ & 0.810 & 1.032 & 1.054 \\
\hline Final $R$ indices $I>2 \sigma(I)^{\mathrm{a}}$ & $\begin{array}{c}\mathrm{R} 1=0.0426 \\
\mathrm{wR} 2=0.0872\end{array}$ & $\begin{array}{c}\mathrm{R} 1=0.0282 \\
\mathrm{wR} 2=0.0774\end{array}$ & $\begin{array}{c}\mathrm{R} 1=0.0516 \\
\mathrm{wR} 2=0.1050\end{array}$ \\
\hline$R$ indices (all data) ${ }^{\mathrm{a}}$ & $\mathrm{R} 1=0.0922$ & $\begin{array}{c}\mathrm{R} 1=0.0351 \\
\mathrm{wR} 2=0.0790\end{array}$ & $\begin{array}{c}\mathrm{R} 1=0.0823 \\
\mathrm{wR} 2=0.1297\end{array}$ \\
\hline
\end{tabular}

${ }^{\mathrm{a}} R_{1}=\sum\left\|F_{o}\left|-F_{c} \| / \sum\right| F_{o} \mid ; R_{2}=\left\{\sum\left[w\left(F_{o}^{2}-F_{c}^{2}\right)^{2}\right] / \sum\left[w F_{o}^{a}\right]\right\}^{1 / 2}\right.$. 
Table 2. Selected bond lengths $(\AA)$ and angles $\left({ }^{\circ}\right)$ for $\mathbf{1}, \mathbf{3}$ and $\mathbf{4}$.

\begin{tabular}{|c|c|c|c|c|}
\hline \multirow[b]{2}{*}{ Complex 1} & \multicolumn{2}{|c|}{ Bond lengths } & \multicolumn{2}{|c|}{ Bond angles } \\
\hline & $\mathrm{Cu} 1-\mathrm{N} 1$ & $1.912(3)$ & N2-Cu1-N1 & $93.24(13)$ \\
\hline & $\mathrm{Cu} 1-\mathrm{N} 2$ & $1.923(3)$ & $\mathrm{O} 2-\mathrm{Cu} 1-\mathrm{O} 1$ & $90.12(11)$ \\
\hline & $\mathrm{Cu} 1-\mathrm{O} 1$ & $1.956(3)$ & $\mathrm{O} 1-\mathrm{Cu} 1-\mathrm{N} 1$ & $91.36(12)$ \\
\hline & $\mathrm{Cu} 1-\mathrm{O} 2$ & $1.955(3)$ & $\mathrm{O} 1-\mathrm{Cu} 1-\mathrm{N} 2$ & $158.81(14)$ \\
\hline & $\mathrm{Cu} 2-\mathrm{N} 4$ & $1.982(3)$ & $\mathrm{N} 4-\mathrm{Cu} 2-\mathrm{N} 4 \_4$ & $180.000(1)$ \\
\hline & $\mathrm{Cu} 2-\mathrm{N} 4 \_4$ & $1.982(3)$ & $\mathrm{O} 3-\mathrm{Cu} 2-\mathrm{N} 4$ & $88.10(12)$ \\
\hline & $\mathrm{Cu} 2-\mathrm{O} 3$ & $2.003(3)$ & $\mathrm{O} 3-\mathrm{Cu} 2-\mathrm{O} 4$ & $87.89(12)$ \\
\hline & $\mathrm{Cu} 2-\mathrm{O} 3 \_3$ & $2.003(3)$ & O3-Cu2-O4_4 & $92.11(12)$ \\
\hline & $\mathrm{Cu} 2-\mathrm{O} 4$ & $2.259(3)$ & $\mathrm{O} 3-\mathrm{Cu} 2-\mathrm{O} 3 \_3$ & $180.00(15)$ \\
\hline & $\mathrm{Cu} 2-\mathrm{O} 4 \_4$ & $2.259(3)$ & & \\
\hline & \multicolumn{4}{|c|}{$\omega 25.14$} \\
\hline \multirow[t]{7}{*}{ Complex 3} & $\mathrm{Cu} 1-\mathrm{N} 1$ & $1.935(17)$ & $\mathrm{N} 2-\mathrm{Cu} 1-\mathrm{N} 1$ & $92.95(7)$ \\
\hline & $\mathrm{Cu} 1-\mathrm{N} 2$ & $1.926(17)$ & $\mathrm{O} 2-\mathrm{Cu} 1-\mathrm{O} 1$ & $88.92(6)$ \\
\hline & $\mathrm{Cu} 1-\mathrm{O} 1$ & $1.954(14)$ & $\mathrm{O} 1-\mathrm{Cu} 1-\mathrm{N} 1$ & $89.78(7)$ \\
\hline & $\mathrm{Cu} 1-\mathrm{O} 2$ & $1.951(15)$ & $\mathrm{O} 1-\mathrm{Cu} 1-\mathrm{N} 2$ & $174.94(7)$ \\
\hline & N5-O3 & $1.235(2)$ & & \\
\hline & N5-O4 & $1.219(2)$ & & \\
\hline & \multicolumn{4}{|c|}{$\omega 7.91$} \\
\hline \multirow[t]{9}{*}{ Complex 4} & $\mathrm{Cu} 1-\mathrm{N} 1$ & $1.994(3)$ & $\mathrm{N} 2-\mathrm{Cu} 1-\mathrm{N} 1$ & $90.53(13)$ \\
\hline & $\mathrm{Cu} 1-\mathrm{N} 2$ & $1.959(3)$ & $\mathrm{O} 2-\mathrm{Cu} 1-\mathrm{O} 1$ & $90.14(13)$ \\
\hline & $\mathrm{Cu} 1-\mathrm{O} 1$ & $1.974(3)$ & $\mathrm{O} 1-\mathrm{Cu} 1-\mathrm{N} 1$ & $154.97(13)$ \\
\hline & $\mathrm{Cu} 1-\mathrm{O} 2$ & $1.951(3)$ & $\mathrm{O} 1-\mathrm{Cu} 1-\mathrm{N} 2$ & $177.86(13)$ \\
\hline & $\mathrm{Cu} 1-\mathrm{N} 4$ & $2.349(3)$ & $\mathrm{O} 2-\mathrm{Cu} 1-\mathrm{N} 4$ & $92.27(12)$ \\
\hline & & & N2-Cu1-N4 & $89.60(13)$ \\
\hline & & & $\mathrm{O} 1-\mathrm{Cu}-\mathrm{N} 4$ & $104.28(12)$ \\
\hline & & & $\mathrm{N} 1-\mathrm{Cu} 1-\mathrm{N} 4$ & $100.66(12)$ \\
\hline & \multicolumn{4}{|c|}{$\omega 25.09$} \\
\hline
\end{tabular}

$\omega=$ Angle between $\mathrm{CuO} 2$ and $\mathrm{CuN} 2$ planes

planer and completed by two oxygen $(\mathrm{O} 1, \mathrm{O} 2)$ from the co-ligand hfacac and two nitrogen donors (N1, N2) from 4-nimpdpm in bis-chelating manner. The distortion from ideal square planar geometry has been estimated from interplanar angle $(\omega)$ between the planes containing $\mathrm{N}(1)-\mathrm{Cu}(1)-\mathrm{O}(2)$ and $\mathrm{N}(2)-\mathrm{Cu}(1)-$ $\mathrm{O}(1)$ which falls to be $84.25^{\circ}$. The $\mathrm{Cu}-\mathrm{N}$ bond distances are comparable to the $\mathrm{Cu}-\mathrm{N}$ separations in other related systems. ${ }^{20-22,38}$ Further, the $\mathrm{Cu}-\mathrm{N}$ distances are slightly smaller, while $\mathrm{Cu}-\mathrm{O}_{\text {hfacac }}$ distances are slightly longer in comparison to $\mathbf{1}$ having hfacac as an ancillary ligand. The bond angles $\mathrm{N} 1-\mathrm{Cu}-\mathrm{N} 2, \mathrm{O} 1-\mathrm{Cu}-\mathrm{O} 2$ are 92.95 and $88.92^{\circ}$, respectively. The angle between $\mathrm{CuO}_{2}$ and $\mathrm{CuN}_{2}(\omega)$ planes is $7.91^{\circ}$, which further suggested distortion from square planar geometry.

The polymeric complex $\mathbf{4}$ crystallized in orthorhombic system with $P_{212121}$ space group. Asymmetric unit contains two $\mathrm{Cu}(\mathrm{II})$, one 4-bzimpdpm ligand and one acac group. Two $\mathrm{Cu}$ (II) centres are separated by 4bzimpdpm spacer with a $\mathrm{Cu} \cdots \mathrm{Cu}$ distance of $13.88 \AA$.

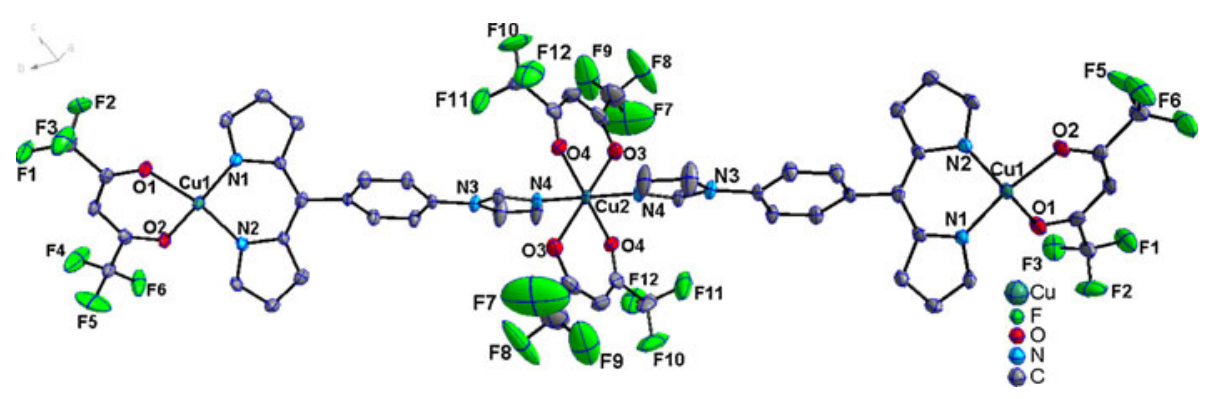

Figure 1. Crystal structure of $\mathbf{1}$ (hydrogen atoms omitted for clarity). 


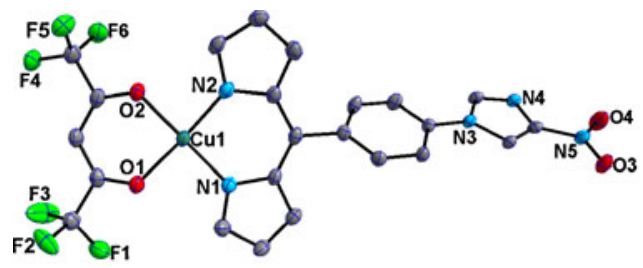

(a)

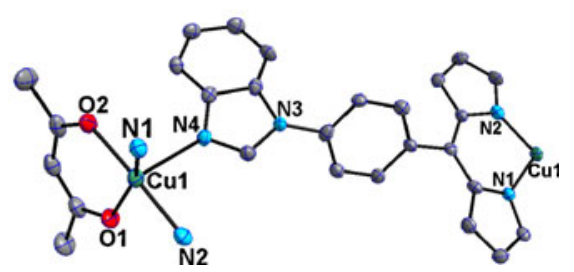

(b)

Figure 2. Crystal structure of $\mathbf{3}$ (a) and $\mathbf{4}$ (b) hydrogen atoms omitted for clarity.

A 1D linear polymeric chain is constructed upon extending the asymmetric unit. The copper (II) centres in the polymeric chain adopted distorted square pyramidal geometry defined by two oxygen donors from acac, two nitrogens from 4-bzimpdpm and the meso-benzimidazoyl nitrogen. Three $\mathrm{Cu}$ (II) centres in 1D polymeric chain oriented in such a way that it generats isosceles triangle with side distances of $13.192 \times 13.192 \times 15.754 \AA$. The interplanar angle $(\omega)$ between plane containing $\mathrm{N}(1)-\mathrm{Cu}(1)-\mathrm{O}(1)$ and $\mathrm{N}(2)$ $\mathrm{Cu}(1)-\mathrm{O}(2)$ is $89.05^{\circ}$, which is very close to the ideal angle of $90^{\circ}$. It strongly suggested that the donor sites $[\mathrm{N}(1), \mathrm{N}(2), \mathrm{O}(1)$ and $\mathrm{O}(2)]$ lie in the same plane. The $\mathrm{Cu}-\mathrm{N}$ bond distances are comparable to the values reported in literature. ${ }^{20-22,38}$ The $\mathrm{Cu}-\mathrm{N}$ (benzimidazolyl) bond distances are $2.349 \AA$. The $\mathrm{Cu}-\mathrm{N}$ and $\mathrm{Cu}-\mathrm{O}$ bond distances are relatively longer than those in $\mathbf{1}$ and 2. The bite angles $\mathrm{N} 1-\mathrm{Cu}-\mathrm{N} 2, \mathrm{O} 2-\mathrm{Cu} 1-\mathrm{O} 1, \mathrm{O} 2-$ $\mathrm{Cu} 1-\mathrm{N} 4, \mathrm{~N} 2-\mathrm{Cu} 1-\mathrm{N} 4, \mathrm{O} 1-\mathrm{Cu} 1-\mathrm{N} 1$, and $\mathrm{O} 1-\mathrm{Cu} 1-\mathrm{N} 2$ suggested slightly distorted square pyramidal geometry about the $\mathrm{Cu}$ (II) centre (table 2).

\subsection{Supramolecular assemblies through weak interactions}

The weak interaction studies revealed the presence of various types of weak interactions leading to interesting motifs. Complex 1 displayed $\mathrm{C}-\mathrm{H} \cdots \mathrm{O}(3.615 \AA)$ and $\mathrm{C}-\mathrm{H} \cdots \pi(3.57-3.74 \AA)$ interactions leading to formation a bi-layer structural motif (figure S7). The outer layer of this motif consists of hfacac fragments, wherein molecules have anti-parallel arrangement. In complex 3, C-F $\cdots \pi(3.14 \AA), \mathrm{C}-\mathrm{H} \cdots \pi \quad(3.61 \AA)$, $\pi \cdots \pi \quad(3.29-3.37 \AA)$ interactions lead to ladder like motif (figure S8), while $\mathrm{C}-\mathrm{H} \cdots \mathrm{O}(2.89 \AA)$, $\mathrm{C}-\mathrm{H} \cdots \mathrm{N}(3.10 \AA)$ and $\mathrm{C}-\mathrm{H} \cdots \pi(3.48 \AA)$ interactions in $\mathbf{4}$ are involved in the creation of independent infinite 1D polymer (figure S9).

\section{Conclusion}

Through this contribution we have presented three novel meso-substituted dipyrrin ligands, and heteroleptic complexes $\quad\left[\mathrm{Cu}_{3}(4-\mathrm{impdpm})_{2}(\mathrm{hfacac})_{4}\right]$, [Cu(4-nimpdpm)(acac)], [Cu(4-nimpdpm)(hfacac)], $\left[\{\mathrm{Cu}(4 \text {-bimpdpm })(\mathrm{acac})\}_{\mathrm{n}}\right]$, and $[\{\mathrm{Cu}(4$-bimpdpm)(hfacac) $\left.\}_{n}\right]$, based on it. The $\mathrm{Cu}(\mathrm{II})$ complexes impart acetylacetonato (acac) and hexafluoroacetylacetonato (hfacac) groups as ancillary ligands. It has been observed that proper functionalization of heteroditopic dipyrrins can lead to a variety of extended architectures upon interaction with $\mathrm{Cu}(\mathrm{acac})_{2}$ and $\mathrm{Cu}(\mathrm{hfacac})_{2} \cdot \mathrm{H}_{2} \mathrm{O}$. Further, it has been demonstrated that the mesosubstituent influences optical properties of the resulting complexes. This approach seems promising for the development of novel heteroleptic complexes.

\section{Supplementary materials}

$\mathrm{X}$-ray crystallographic files in CIF format. Preparation of aldehydes, ESI-MS of $\mathbf{1 - 5}$ and some interesting motifs resulting from weak interactions in $\mathbf{1 , 3}$ and $\mathbf{4}$ are given as electronic supplementary information. Helical 1D chain structure of 4 (S6), UV-vis and fluorescence spectra of 1-5 (S10) and table for photophysical properties of 1-5 (table S1). For details, see www.ias.ac.in/chemsci website.

\section{Acknowledgements}

We thank the Council of Scientific and Industrial Research (CSIR), New Delhi for financial support through the scheme 01(2361)/10/EMR-II and for awarding JRF (09/013(0210)/-2009-EMR-I) to RKG. We are also thankful to In-charge, National Single Crystal X-ray Diffraction Laboratory, Indian Institute of Technology, Powai, Mumbai and Indian Institute of Technology, Kanpur for extending single crystal X-ray facilities. 


\section{References}

1. Przychodzén P, Korzeniak T, Podgajny R and Sieklucka B 2006 Coord. Chem. Rev. 2502234

2. Beghidja A, Rabu P, Rogez G and Welter R 2006 Chem. Eur. J. 127627

3. Fu R, Xiang S, Hu S, Wang L, Li Y, Huang X and Wu X 2005 Chem. Commun. 425292

4. Seo J S, Whang D, Lee H, Jun S I, Oh J, Jeon Y J and Kim K 2000 Nature 404982

5. Eddaoudi M, Moler D B, Li H, Chen B, Reineke T M, O'Keefe M and Yaghi O M 2001 Acc. Chem. Res. 34 319

6. Constable E C 2008 Coord. Chem. Rev. 252842

7. Ferey G, Mellot-Draznieks C, Serre C and Millange F 2005 Acc. Chem. Res. 38217.

8. Maspoch D, Ruiz-Molina D and Veciana J 2007 Chem. Soc. Rev. 36770

9. Kitagawa S, Kitaura R and Noro S I 2004 Angew. Chem. Int. Ed. 432334

10. Bradshaw D, Claridge J B, Cussen E J, Prior T J and Rosseinsky M J 2005 Acc. Chem. Res. 38273

11. Kitagawa S and Uemura K 2005 Chem. Soc. Rev. 34 109

12. Khlobystov A N, Blake A J, Champness N R, Lemenovskii D A, Majouga A G, Zyk N V and Schröder M 2001 Coord. Chem. Rev. 222155

13. Furukawa S, Hirai K, Nakagawa K, Takashima $Y$, Matsuda R, Tsuruoka T, Kondo M, Haruki R, Tanaka D, Sakamoto H, Shimomura S, Sakata O and Kitagawa S 2009 Angew. Chem., Int. Ed. 481766

14. Kitaura R, Kitagawa S, Kubota Y, Kobayashi T C, Kindo K, Mita Y, Matsuo A, Kobayashi M, Chang H C, Ozawa T C, Suzuki M, Sakata M and Takata M 2002 Science 2982358

15. Matsuda R, Kitaura R, Kitagawa S, Kubota Y, R. Belosludov V, Kobayashi T C, Sakamoto H, Chiba T, Takata M, Kawazoe Y and Mita Y 2005 Nature 436 238

16. Tzeng B C, Chiu T H, Chen B S and Lee G H 2008 Chem. Eur. J. 145237

17. Banerjee R, Phan A, Wang B, Knobler C, Furukawa H, O'Keeffe M and Yaghi O M 2008 Science 319939

18. Prasad T K and Rajasekharan M V 2008 Cryst. Growth Des. 81346

19. Mohamed A A, Mayer A P, Abdou H E, Irwin M D, Perez L M, Fackler J P, 2007 Inorg. Chem. 4611165

20. Halper S R, Malachowski M R, Delaney H M and Cohen S M 2004 Inorg. Chem. 431242
21. Halper S R and Cohen S M 2004 Angew. Chem. Int. Ed. 432385

22. Pogozhev D, Baudron S A and Hosseini M W 2010 Inorg. Chem. 49331

23. Ulrich G, Goze C, Guardigli M, Roda A and Ziessel R 2005 Angew. Chem. Int. Ed. 443694

24. Muthukumaran K, Zaidi S H H, Yu L, Thamyongkit P, Calder M E, Sharada D S and Lindsey J S 2005 J. Porphyr. Phthalocya. 9745

25. MacDonald I J and Dougherty T J 2001 J. Porphyr. Phthalocya. 5105

26. Smith K M, (ed.) Porphyrins and Metalloporphyrins In: Synthesis and preparation of porphyrin compounds, Elsevier, Amsterdam 1975 (Chapter 2) 459p

27. Littler B J, Miller M A, Hung C H, Wagner R W, O'Shea D F, Boyle P D and Lindsey J S 1999 J. Org. Chem. 64 1391 and references therein

28. Lindsey J S 2010 Account Chem. Res. 43300 and references cited therein

29. Maeda H, Hasegawa M, Hashimoto T, Kakimoto T, Nishio S and Nakanishi T 2006 J. Am. Chem. Soc. 128 10024

30. Garibay S J, Stork J R, Wang Z, Cohen S M and Telfer S G 2007 Chem. Commun. 4881

31. Hall J D, McLean T M, Smalley S J, Waterland M R and Telfer S G 2010 Dalton Trans. 437

32. Perrin D D, Armango W L F and Perrin D R 1986 Purification of laboratory chemicals, Oxford, U.K.: Pergamon

33. Magdolen P, Meciarova M and Toma S 2001 Tetrahedron $\mathbf{5 7} 4781$

34. Jones M M 1959 J. Am. Chem. Soc. 813188

35. Sheldrick G M 1997 SHELXL 97, Program for Refining Crystal Structures, University of Gottingen, Germany 367

36. Sheldrick G M 1990 SHELXS 97, Program for the Solution of Crystal Structures, University of Gottingen, Germany

37. Wood T E and Thompson A 2007 Chem. Rev. 1071831 and reference therein

38. Delgado S, Munoz A, Medina M E and Pastor C J 2006 Inorg. Chim. Acta 359109

39. Yadav M, Singh A K, Maiti B and Pandey D S 2009 Inorg. Chem. 487593 and reference therein

40. Yadav M, Kumar P, Singh A K, Ribas J and Pandey D S 2009 Dalton Trans. 9929

41. Yu L, Muthukumaran K, Sazanovich I V, Kirmaier C, Hindin E, Diers J R, Boyle P D, Bocian D F, Holten D and Lindsey J S 2003 Inorg. Chem. 426629

42. Gao L, Wang Y, Wang J, Huang L, Shi L, Fan X, Zou Z, Yu T, Zhu M and Li Z 2006 Inorg. Chem. 456844 